\title{
Framing organizational social media: a longitudinal study of a hotel chain
}

\section{Karin Högberg $^{1}$ (D) $\cdot$ Anna Karin Olsson ${ }^{1}$ (D)}

Received: 1 March 2019 / Accepted: 1 March 2019 / Published online: 18 March 2019

(c) The Author(s) 2019

\begin{abstract}
The development of social media in the past decade has transformed the hospitality and tourism industry. There is, however, limited empirical research on how individual employees and groups of employees within organizations make sense of new technology, such as social media, over time. In this paper we focus on the individual and organizational level by exploring how hotel employees and managers make sense of organizational social media over a 4-year period. The perceived usefulness of social media is studied in an organizational setting by applying technological frames as a theoretical framework. The study is a longitudinal case study that includes time both during and after the implementation of social media in an international hotel chain in Europe. A total of 37 in-depth qualitative interviews were conducted at 14 hotels as well as additional observations on site and on social media platforms. The study contributes to existing literature by investigating organizational social media use over time.
\end{abstract}

Keywords Organizational social media $\cdot$ Technological frames $\cdot$ Socio-cognitive $\cdot$ Information technology use $\cdot$ Longitudinal research $\cdot$ Hospitality industry

\section{Introduction}

The development of social media in the past decade has transformed the hospitality and tourism industry. Compared to other organizations, hotel have been late adopters of social media. Thus social media has drastically challenged and changed the way hotel organizations produce, market and deliver their services, hence also their internal and external communication (Sigala and Gretzel 2017). Social media have become ubiquitous in the workplace and have changed how organizations communicate and interact

Karin Högberg

karin.hogberg@hv.se

Anna Karin Olsson

anna-karin.olsson@hv.se

1 School of Business, Economics and IT, University West, 46186 Trollhättan, Sweden 
with customers. Compared to other information technologies used in organizational contexts, social media were initially designed as online networks for individual, private use and not intended to function as organizational tools (Treem et al. 2015). However, due to external pressure and a worldwide adoption of social media, organizations are also starting to use these social platforms in order to be competitive and to be close to customers.

It is widely recognized that when individuals and groups use new technology they form perceptions, mental maps or cognitive structures in order to make sense of the technology (Orlikowski and Gash 1994). Earlier studies of information technology (IT) use in organizations have found that employees form perceptions of IT while they are using them at work (Young et al. 2016). As employees interact with new IT and discuss it with other employees they evaluate its usefulness and make sense of how the technology can contribute to their work tasks (Treem et al. 2015). In this interaction, groups of employees as well as individual employees within the organization create "technological frames", i.e., expectations and assumptions regarding what IT should be used and what use it can be (Orlikowski and Gash 1994). Technological frames are social constructions and individuals may hence have different interpretations of the usefulness of IT and use it differently.

Orlikowski and Gash's (1994) concept of technological frames has been applied in earlier studies to examine the use of IT in organizations, yet little is known about the technological frames of social media in organizational settings over time (Treem et al. 2015). Hence, despite the increased use of social media in organizations there is still a research gap concerning how social media platforms are used in organizational settings over time and how employees make sense of them in their day-to-day-work practices over time (Aral et al. 2013; Treem et al. 2015).

The challenge of using social media in organizational work practices has been highlighted as an important research venue that needs further investigation (Aral et al. 2013). Social media has become an important research topic in several overlapping fields, such as organizational communication, marketing, advertising and public relations. A large amount of research has been published on social media use in organizational contexts (e.g., Majchrzak et al. 2013; Treem et al. 2015). However, these studies are mainly concerned with fragmented use of social media such as enterprise social media or social media marketing (e.g., Majchrzak et al. 2013; Ellison et al. 2015). In response to recent calls to focus on the use of social media in organizations over time (Aral et al. 2013; Schlagwein and Hu 2017), this paper seeks to investigate what implications perceptions held by employees and managers within organizations have on organizational use of social media over time. Based on this the research questions are as follows: What are the technological frames of organizational groups within the hotel organizations? How do these technological frames shape the organizational use of social media over time? 


\section{Organizational social media}

Social media are often described as Internet-based tools that allow users to easily create, edit, and/or link to content or to other creators of content (Kaplan and Haenlein 2010). Unlike the IT the employees may encounter in organizational settings, social media has proliferated outside organizational contexts prior to being introduced to the workplace (Treem et al. 2015). Both practitioners and researchers have accordingly described social media as one of the most transformative and disruptive impacts of IT for all aspects of business, from marketing, finance, and operations to human resources, knowledge management, and innovation management (Aral et al. 2013). Researchers also argue that social media is expected to generate unprecedented and intense changes in social interactions and exchanges within and beyond the organization's boundaries (Van Osch and Coursaris 2017, 2017 ). Earlier research on social media use in organizational settings has mainly focused on the use of specific social media platforms (Schlagwein and Hu 2017; Högberg 2018). Researchers have also made clear distinctions between internal and public use of social media (Schlagwein and $\mathrm{Hu}$ 2017). Such internal use, often referred to as enterprise social media (ESM), describes social media used for example in knowledge management or knowledge sharing within organizations (Munar 2012; Leonardi 2011; Leonardi et al. 2013; Razmerita et al. 2014; Treem and Leonardi 2012; Mansour 2013). In contrast, social media used by organizations for external communication often goes under the term social media marketing (SMM) and refers to marketing activities and communication conducted by organizations through social media channels (Michaelidou et al. 2011; Minazzi 2015). However, these fragmented examinations of social media in organizations has been questioned by researchers who argue that researchers must look at more general use of social media in organizational contexts that includes both public social media and enterprise social media (Aral et al. 2013; Schlagwein and Hu 2017). For example, Van Osch and Coursaris (2013) argue that social media used by and in organizations could be referred to as organizational social media (OSM). Van Osch and Coursaris (2013, p. 54) emphasized the need for a more general view and research on social media used by organizations but also a wider definition of the use of social media in and by organizations. Therefore they define OSM as:

technology artefacts, both material and virtual, that support various intraand extra-organizational actors-including management, employees and external stakeholders-in a multiplicity of organizational communication activities for producing user-generated content, developing and maintaining social relationships, or enabling other computer-mediated interactions and collaborations in the context of a specific organization and its environment.

A key gap in the literature on social media is a lack of analysis that considers more general use and impact of all this social media use in organizations (Larson and Watson 2011; Aral et al. 2013; Schlagwein and Hu 2017). Hence, in this study we take the approach of using the perspective of organizational social media 
(Van Osch and Coursaris 2013) in order to embrace a more extensive and general use of social media in an organizational context. Furthermore, researchers have called for more research on the creation of technological frames by individuals and organizational sense-making related to IT innovation such as social media, which happens not only within firm boundaries, but also among firms and with stakeholders (Young et al. 2016). By doing so, vendors, customers/user organizations, academics, consultants, and other stakeholder groups become relevant social groups, whose sense-making, actions, and interactions shape technological artefacts (Wilson and Howcroft, 2005; Davidson 2006). We therefore emphasize a more extensive use of organizational social media use including social media marketing and enterprise social media in this study in order to examine frames held by employees and social groups within the studied organizations.

\subsection{Social media in hospitality}

It can be argued that the hotel industry is going through a transformation where its organizational service context is expanded, since many of the service encounters take place online (Minazzi 2015). The hotel industry faces new challenges with the introduction of social media that call for research. Earlier research has focused on specific use of social media in and by hotels (Garrido-Moreno and Lockett 2016). One stream of research has concentrated on social media as a platform for maintaining relationships with customers, both from the customer and organizational perspective. Buhalis and Neuhofer (2017) studied value and co-creation of service with social media through the lens of service-dominant logic and found that social media have become a facilitator of change and have empowered consumers to connect, engage, participate and co-create their own experiences and value. Similarly, Garrido-Moreno et al. (2018) examined the impact of social media use and how value could be co-created. Furthermore, earlier research has investigated the use of social media platforms for marketing and branding. Nyangwe and Buhalis (2018) used a single case study approach, the Marriott Hotels International, to study how co-creation of brand value is being carried out between the firm and its stakeholders. Chan and Guillet (2011) studied the strategic role of social media marketing and how social media could support hotels to create more valuable content and information to their customers.

A second stream of earlier research has also put a large emphasis on the increased use of online reviews, and the importance of user-generated content has been widely analyzed. Earlier research reveals that user-generated content and word-of-mouth on social media sites is one of the most influential ways to form consumer attitudes about a product or service (Zhu and Zhang 2010; Ayeh et al. 2013; Podnar and Javernik 2012). The relationship between stakeholders and organizations has also been emphasized in social media research (Hennig-Thurau et al. 2013; Viglia et al. 2018). Social media has created a lack of control for organizations as stakeholders are becoming more empowered (Viglia et al. 2018). Researchers have put a lot of emphasis on word-of-mouth and its implications for consumer decision-making (see e.g., Crotts et al. 2009; Sigala and Gretzel 2012; Sigala and Gretzel 2017) that 
reveals that social media has played an important role in affecting hotel guests' purchase behavior (Anderson 2012; Zhang et al. 2019). Anderson (2012) studied the effects of online review ratings from Travelocity.com. The findings revealed that the number of consumers consulting reviews before booking has increased over time and that there is a relationship between the hotels' rating and its pricing. Similarly, Xiang et al. (2017) investigated the effects of online reviews on customer attitudes, in a comparative study that examined three major online review platforms, TripAdvisor, Expedia, and Yelp. Their findings show that there are massive inconsistencies in the representation of the hotel industry on these platforms. Mainly, online reviews vary noticeably in terms of their linguistic characteristics and semantic features. Berezina et al. (2016) used a text-mining approach to compare the differences between positive and negative online reviews. Their study revealed that disappointed customers are more likely to mention the tangible parts of hotels in their online reviews. From an organizational point of view, Silveira-Chaves et al. (2012) investigated how hotels respond to online reviews on sites like TripAdvisor, while Sparks and Browning (2011) discovered that hotel customers determined what hotel to book depending on ratings in online reviews. Mkono and Tribe (2017) studied the different roles of the consumer related to reviewing hospitality experiences.

A third stream of research has focused on the organizational point of view, for example on the possibilities of market services and products with social media (Moro and Rita 2018). de Rosario et al. (2013) analyzed the use of social media by the world's 50 largest hotel chains, and discovered that the size and age of the hotel chain influenced the use of social media. Högberg (2017) investigated how social media is used in a broad range of organizational processes such as service and . Price and Starkov (2006) studied hotel blogs and providing information to customers found that hotels that encouraged visitors to write comments in order to get rewards created an ethical dilemma and that the credibility of the content on company blogs was questioned. Huang et al. (2011) explored blogs and marketing strategies from the supplier's perspective. Furthermore, the use of specific social network sites, Facebook in particular, has been of great interest to the research field (Di Pietro and Pantano 2012; Huang et al. 2010). Kasavana et al. (2010) accepted the business potential for travel companies to use Facebook in international electronic marketing. However, there has been relatively little research on the social media and firm-generated content (e.g. promotion) in the hospitality and tourism contexts (Kim et al. 2015b). Hence, social media research in the hospitality and tourism areas lacks diversity, and research on organizational use of social media is limited (Lu et al. 2018). The present study follows this third stream and aims to contribute by taking the organizational perspective on organizational social media use in a hotel context.

\section{Theoretical framework: technological frames}

Earlier research has to a great extent studied why and how individuals and organizations adopt and implement IT (e.g., Davis et al. 1989; Kwon and Zmud 1987; Rogers 1995; Davidson 2002; Fulk and Gould 2009) and the process by which organizations integrate technological innovations into their existing organizational routines 
(Zammuto et al. 2007; Yoo 2010). A large amount of research on IT in organizations has found that individuals form perceptions of technologies during the practice of work (Orlikowski 1992; Fulk 1993; Jian 2007). When employees interact with new technology they evaluate its usefulness in relation to their work tasks (Treem et al. 2015). The implementation of IT in organizations is often related to change and therefore also closely related to an interpretative process (Barr 1998; Weick 1994; Weick et al. 2005). That is, employees act on their interpretations of the world, and thus their understandings must change if their actions are to change. Hence, how people make sense of technology is an important factor when implementing a strategy for IT use. Many studies have focused on the relationship between how technological frames affect technology use in an organization and the way employees use them at work. However, compared to other IT tools used in organizations, social media platforms such as Twitter and Facebook were designed for private use, not organizational use, and hence individuals have often been introduced to them in private contexts (Treem et al. 2015). This study is focused on the use of social media in hotel organizations over time and hence the framework of technological frames has been used in order to analyze the interpretations of organizational use of social media.

The framework was introduced by Orlikowski and Gash, referring to frames as social constructs that include "assumptions, knowledge, and expectations, expressed symbolically through language, visual images, metaphors, and stories" (1994: 175). They suggested that frames exist on individual and group levels, are flexible in structure and content, and may shift over time. Different individuals can hold dissimilar views of the purpose of technology, and technology can be interpreted and used in different ways (Pinch and Bijker 1984). Prior studies have applied the framework of technological frames to examine IT in organizations over a short period of time (Blegind Jensen and Aanestad 2007; Mishra and Agarwal 2010). Nevertheless, these studies have been criticized since they may be viewed as snapshots of time and do not take into consideration how frames might change over time (Davidson 2006; Lin and Silva 2005; Olesen et al. 2013; Young et al. 2016). Hence, there is a need for studying the ongoing use of IT in an organization over time, which this study does. More precisely, this study focuses on the perceived usefulness of an introduction and use of social media in an organizational setting.

Earlier studies of cognition have mainly focused on individual decision-making and frames, whereas the organizational and information systems (IS) research often focuses on group frames (Orlikowski and Gash 1994). In this study, we emphasize both individual and group frames in order to understand and analyze organizational use of social media over time. A frame has several features, but fundamentally, a frame is a mechanism used by individuals to make sense of new phenomena. For example, a certain group of individuals can generate or share the same beliefs and assumptions towards certain phenomena. Theories describing social construction of technology define social groups based on similarities in their interpretation of technologies (Young et al. 2016). Shared frames or shared understanding of how the information system will support the organizational strategy is crucial to how the introduction and use will turn out (Orlikowski and Gash 1994). Orlikowski and Gash (1994) also point out that there are dominant frames held by social groups. 
These are able to dominate the weaker frames of other social groups and individuals and can also affect groups and individuals into accepting or resisting the technology.

Earlier research suggests that inconsistency within a group can be as problematic as frame incongruence between groups and has implications for the organizational use of IT (Young et al. 2016). Orlikowski and Gash (1994) use the term congruence to describe when individuals and groups have the same technological frames. Similarly, incongruence suggests differences in expectations, knowledge and assumptions. An illustration of incongruence is when managers expect technology to change the way the organization does business, while the employees' interpretation is that the technology is supposed to control their work (Orlikowski and Gash 1994). Incongruence can lead to conflicts among groups and affect the use of IT (Young et al. 2016). Compared to frame incongruence between groups, frame inconsistency in groups has received little attention in research (Olesen 2014; Young et al. 2016). Frame inconsistency signifies differences (that is, contradictory or conflicting assumptions and expectations about technology) between individuals within a group (see Fig. 1).

Orlikowski and Gash (1994) view technological frames as covering three domains: (1) the nature of technology refers to the individual's interpretation of technology and understanding of its functionality; (2) technology strategy refers to users' views of why the organization needs to implement the technology; and (3) technology in use refers to the individual's understanding of how the technology can be used on a day-to-day basis and possible consequences related to such use. Young et al. (2016) further developed the set of domains in their study and added technology use and context domains. Individual frames are always set in a particular context. Hence, the same frame can also be active as a reference in a different context, e.g., work or private use of social media. However, the context might constrain an individual's interpretation of the technology and therefore lead to different understandings and use (Hsu 2009).

\subsection{Re-framing and unlearning}

Social media can be viewed, just like other IS and IT, as disruptive in that it requires adaption of knowledge related to organizational work tasks. Researchers argue that organizations need to both learn and unlearn, i.e., to "reframe", in order to adapt to new IT (Olesen et al. 2013). Reframing involves shifting from earlier assumptions and knowledge and unlearning old processes and logics of the industry and organization. As pointed out by Bolman and Deal (1991: 4) frames may create "psychic prisons" that inhibit learning because people "cannot look at old problems in a new light and attack old challenges with different and more powerful tools", i.e., they cannot reframe. Learning and unlearning in an organizational context can be described as a negotiation that often involves a process, in which individuals within and between groups enact their frames and reframe their attitudes towards the new technology. In this process, it is relevant to identify tacit assumptions that profoundly affect how people interact with others in an organizational context (Argyris 1993). Unlearning is considered the "process of which firms eliminate old logics 
and make room for new ones" (Prahalad and Bettis 1986). Klein (1989) argued that "forgetting" must take place on an individual level for unlearning to occur on an organizational level. Hence, unlearning is a way to make way for new cognitive structures and thereby change organizational values and behaviors (Bettis and Prahalad 1995). Recent research by Treem et al. (2015) exemplified this by interpreting individuals' frames as skepticism or optimism towards social media use in organizations. As pointed out by Pinch and Bijker (1984) and Orlikowski and Gash (1994), the frames are strengthened and shaped by the users themselves, e.g., a user can discard knowledge that does not fit into his/her perceptions of what is meaningful, and on the other hand, users might also embrace ideas that are incorrect or unclear. Furthermore, changing circumstances in the surroundings such as industry affect the process of individuals and groups making sense of technology (Young et al. 2016) (Fig. 1).

\section{Methods}

\subsection{Longitudinal case study}

In 2013 the studied international hotel chain started to use social media, which included both the use of social media by the hotel brand and by the individual hotels within the chain, located in seven European countries. Organizationally this meant that the use of social media should be incorporated into both the hotel chain organizational structure as well as the individual hotels. A social media manager was put in charge of creating guidelines and strategies for social media use and in each of the individual hotels one or two employees were chosen to be in charge of this. The process of making sense of new IT and understanding its usefulness changes over time, as individuals use it in their workplace and are exposed to different technologies, hence a longitudinal study was chosen (Davidson 2006; Olesen 2014). Since the purpose of this study was to understand how technological frames might affect organizational social media use, the study uses an interpretive case study methodology (Klein and Myers 1999). A case study design was also used since it is appropriate when studying a "contemporary phenomenon within its real-life context" (Yin 2003: 13). In this paper, the international hotel chain represents a single case with embedded cases, represented by the individual hotels in the study (Yin 2003).

\subsection{Data collection}

The data for this article was generated mainly from semi-structured in-depth interviews, but also from observations at the hotel organizations, online observations of social media platforms and written documents such as social media strategies and guidelines. Over a period of 4 years, 37 interviews including nine follow up interviews were conducted with 28 hotel employees and managers in the international hotel chain (see Appendix 1). These interviews include nine follow-up-interviews. The hotel industry has high employee turnover and besides nine employees, all 


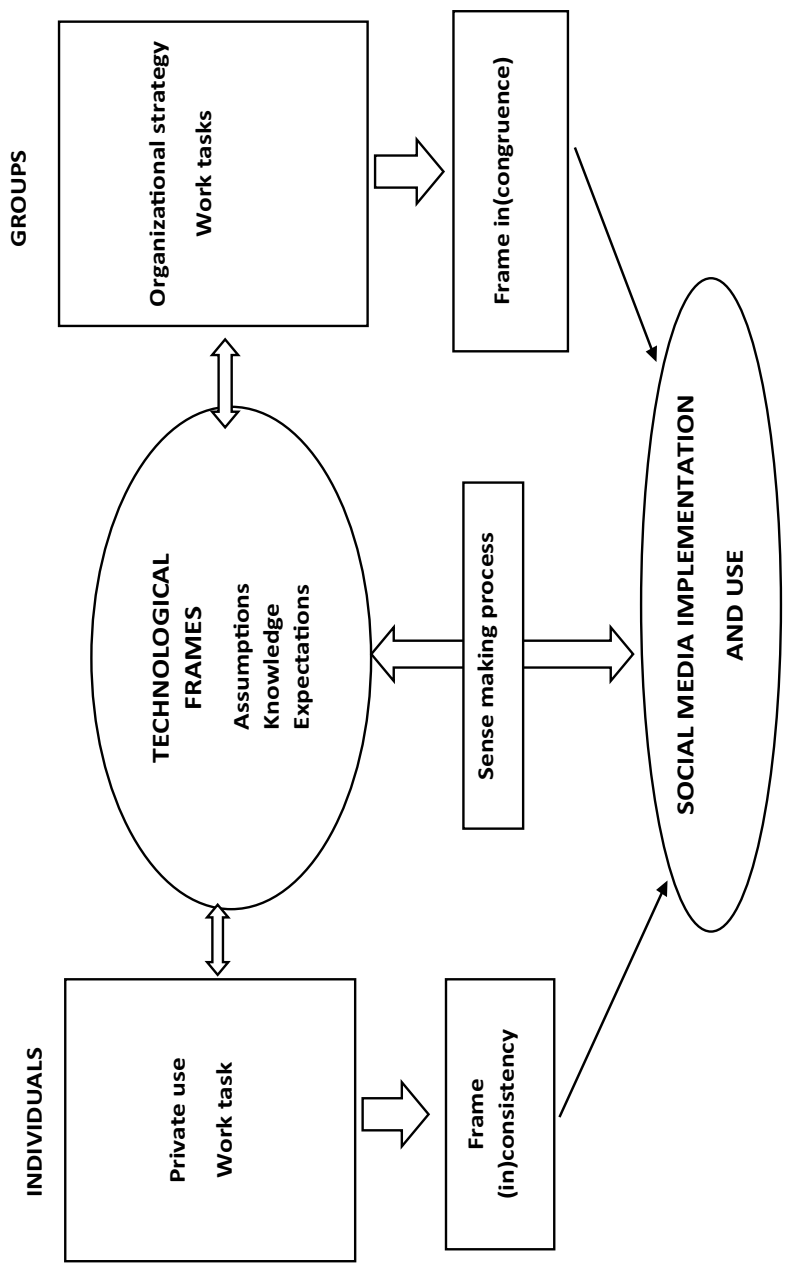

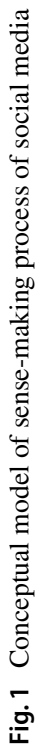


others had changed positions or workplace a year after the first interview, which was also important in the analysis of the social media use. The respondents were selected based on their actual use of social media in each organization and in the hotel chain head offices. All respondents are either working at the hotel chain head offices (referred to as managers) or are organizational members who work with social media at the individual hotels (referred to as employees). Thus the employee group include titles such as local hotel manager, marketing manager or sales manager. Social media use is therefore mandatory for the respondents in the hotel chain. The sampling was conducted through "snowball sampling", i.e., recommendations from other respondents (Kvale 1996). These interviews provide evidence about the technological frames of the key groups for analysis (see Table 1). The initial interviews was conducted in 2013-2014 and had an explorative approach with focus on the managers' work in creating social media strategies and guidelines, and the views of employees at the individual hotels on the hotel chain's decision to use social media and their actual use of it in each hotel. The interview questions also focused on how social media related to other work tasks, such as service and customer interaction. The researchers followed a semi-structured interview procedure (Kvale 1996) to ask questions about each how employee processes usage and perceptions of social media usage in the hotel organizations, as well as about their private social media use to understand their interpretations, assumptions and expectations (technological frames) of social media in the workplace. All interviews began with questions concerning the employees' work tasks and responsibilities and the usage of social media in their workplace, e.g., "Can you describe how your hotel uses social media?" The following questions focused on challenges and use (see Appendix 2). The employees were also asked to reflect on why and how the hotels use social media, which was relevant when analyzing their sense-making processes (cf. Weick 1990) related to social media. The questions were formulated to get insight into their work situation, use and perception of social media, or in other words, how they make sense of the new technology.

The interviews that followed the first round of interviews were conducted regularly during 2015-2017 in order to understand and analyze how the individual employees and managers as well as the social groups had interpreted and used social

Table 1 Organizational groups of users

\begin{tabular}{|c|c|c|}
\hline Group & Composition & Objectives \\
\hline $\begin{array}{l}\text { Management group at hotel } \\
\text { chain level }\end{array}$ & $\begin{array}{l}\text { Members of the social media manage- } \\
\text { ment team including hotel chain } \\
\text { social media manager and members } \\
\text { of the "social media team" (see } \\
\text { Appendix 1) }\end{array}$ & $\begin{array}{l}\text { To manage the social media use } \\
\text { by providing strategies and } \\
\text { policies to the local hotels }\end{array}$ \\
\hline Employees at local hotels & $\begin{array}{l}\text { Employees at } 14 \text { local hotels in seven } \\
\text { European countries, all responsible } \\
\text { for social media use in each hotel } \\
\text { (see Appendix } 1 \text { ) }\end{array}$ & $\begin{array}{l}\text { To manage and use social } \\
\text { media at the local hotels, e.g., } \\
\text { post material in social media } \\
\text { platforms or answer comments } \\
\text { and reviews }\end{array}$ \\
\hline
\end{tabular}


media over time and what implications this had for the hotel organizations. The interviews focused on the employees' ongoing usage of organizational social media and reactions related to management's ongoing adjustments and changes in policy and control of social media within the hotel chain (cf. Davidson and Pai 2004). The interview guides were developed based on the previous interviews and continuous online observations of the hotels' social media activities since the first round of interviews (see Appendices 2 and 3). During 2015-2017 interviews with new managers at the positions as social media content manager and e-commerce manager were also conducted (see Table 2). By conducting interviews continually during a four-year period we could develop an understanding of the organizational social media use over time, but also analyze how individual and group frames had implications for the use of social media in the organizational contexts. Longitudinal studies often have problems with sample attrition, for example, that employees change jobs or organizations go out of business (Bryman and Bell 2015). This has also been an element that affected the design of this study (Fig. 2).

Other sources of data were also used. Written documents including extracts from social media guidelines and policy documents used by the hotels were a source of empirical data. Furthermore, observations and field notes were conducted at the hotels in relation to the interviews (Veal 2011). During visits to the hotels to conduct interviews, the interviewing researcher also got insights into how the hotels use social media to provide guests with information, e.g., information about transportation to the hotel. These observations provided a "customer perspective" and were useful when later discussing the social media use with the employees at the hotels. Participatory observations were also conducted during the visits at the hotels. For example, during the interviews the employees often used their smartphones or tablets to show how they use social media, which gave insight into the organizational use of social media and the respondents' daily work practices (Järvinen 2004; Bryman and Bell 2015). The research notes taken before and after the interviews are full field notes, i.e., detailed notes with information about persons, events and surroundings (Lofland and Lofland 2006). Jotted notes were also taken during the interviews, i.e., keywords and phrases, in order to ask follow-up questions (Lofland and Lofland 2006). Furthermore, online observations were conducted by continuous following of social media content in social media platforms used by the studied hotels during 2013-2017. During these online observations the "Netnography" method (Kozinets 2010) was used. Hence, published content in social media platforms was observed without the researcher participating. These observations gave insights into how social media was used by the hotels and was helpful when conducting the follow-up interviews. Since the study is longitudinal, a timeline was made in order to emphasize the different organizational actions and events that took place during the 4 years. The hermeneutic circle emphasizes a spiral understanding of the data by focusing on the meanings of the parts and then linking them with the whole in an integrative manner (Klein and Myers 1999). In doing so, an understanding of the studied phenomena, in this case identifying the employees' frames of social media, and linking them to actual use could be achieved. The first step in the hermeneutic analysis was to read the transcripts and get insight into the context of the hotel organizations and hotel chain. Then, by going back and forth through the data, a sense-making of the data was created, using open coding processes (Cole and 


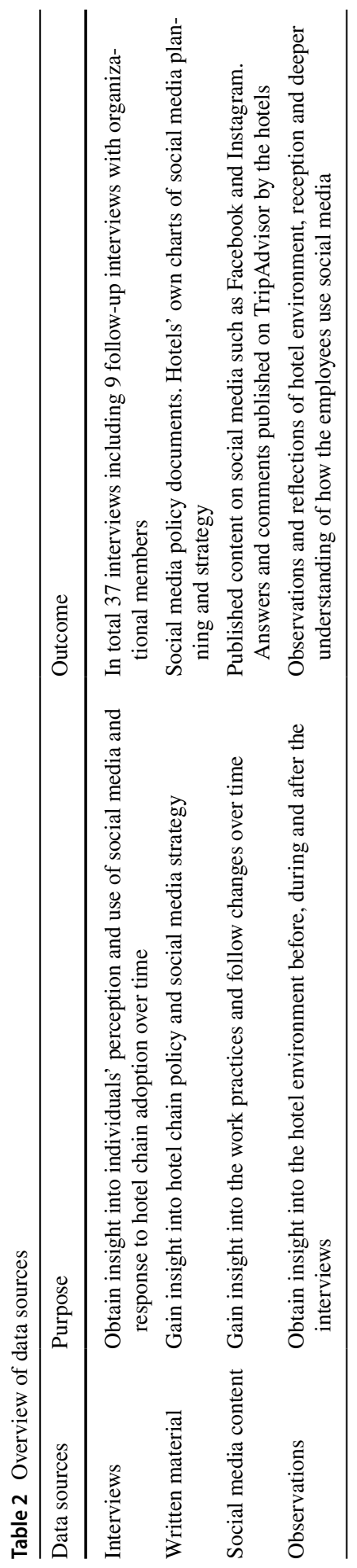




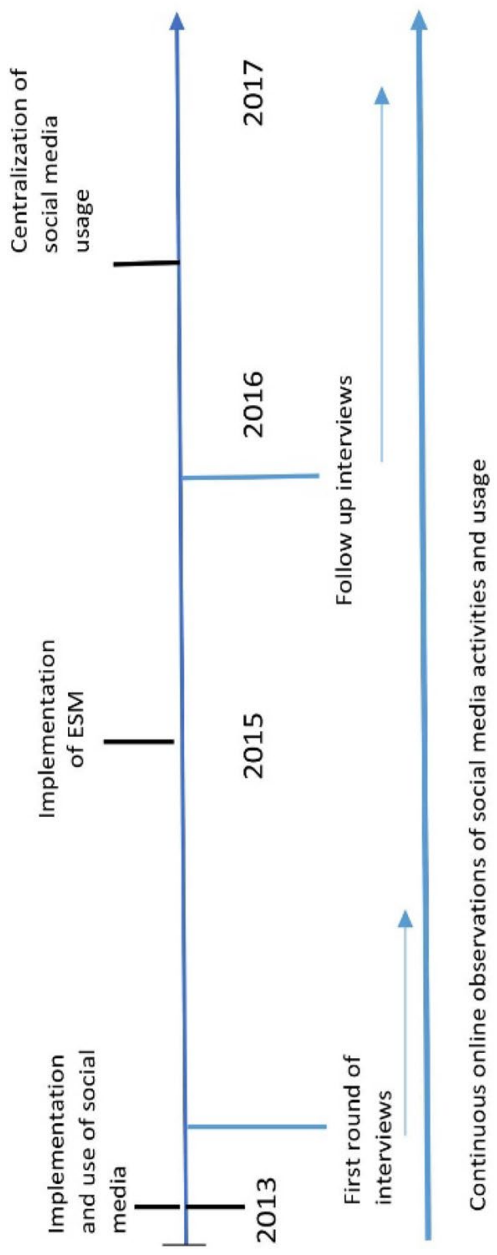

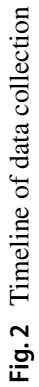


Avison 2007) with fictive names of respondents. The categorization involved grouping of social groups, such as managers and employees (see Table 1), but also doing subcategorizations based on individual frames, e.g., heavy users or non-users. A secondary thematization was also conducted by using the qualitative data analysis software NVivo (Bazeley 2013). This step was also important when trying to understand where the respondents had created their frames, and find possible dominant frames (Orlikowski and Gash 1994). Furthermore, by linking the frames to actual use (technology in use) of social media in the organizations, the second research question could be answered. During the entire hermeneutic analytical circle the data sources from online observations, participatory observations and notes were used in order to create more understanding of the social media use and the respondents' frames.

\subsection{Analysis}

The data analysis was conducted with emphasis on developing certain interpretive understandings of text in light of chosen theoretical concepts and then explaining these meanings for the development of our theoretical arguments. Each individual interview transcript was examined by both authors separately but using the same analytical processes. This involved first reading and understanding the text in each interview transcript and then explaining the data based on theoretical concepts. A simple table comprised of three main columns was used (cf. Miles and Huberman 1994). The columns include the theoretical concepts, empirical quotes, and a brief explanation of how the concept is related to the quote (see Table 3). Initially, understanding the data in terms of identifying key empirical instances and linking these to theoretical concepts was the main focus. The tables were later compared in order to summarize dominant instances and concepts in one shared table to be further examined as illustrated in Table 3.

The empirical data was analyzed using the hermeneutic tradition (Cole and Avison 2007) and one of its core principles, the hermeneutic circle. The hermeneutic circle refers to a tool for analyzing textual data in an iterative, spiral manner (Klein and Myers 1999; Cole and Avison 2007). The hermeneutic circle was applied in order to reveal the respondents' understanding of the meanings and interpretations of social media and identify their technological frames (Klein and Myers 1999; Orlikowski and Gash 1994), but also to establish important relationships across the organizational groups of management and employees (see fig. 1). This way we used interpretive processes of understanding and explanation (Cole and Avison 2007) in order to explain the meanings in the text (interviews) which also is related to the nature of case studies that often have the aim of investigating questions of "why" and "how." An analysis of technological frames requires eliciting an individual's knowledge, assumptions and expectations, and the semi-structured interviews aimed to reveal these frames through language, visual images, metaphors and stories (Orlikowski and Gash 1994). By focusing on the respondents' stories, metaphors and expressions, and sense-making related to social media, an interpretation of their frames was developed (Davidson and Pai 2004). The analysis mainly builds on the interview transcripts and to some extent on the field notes and social media material. 


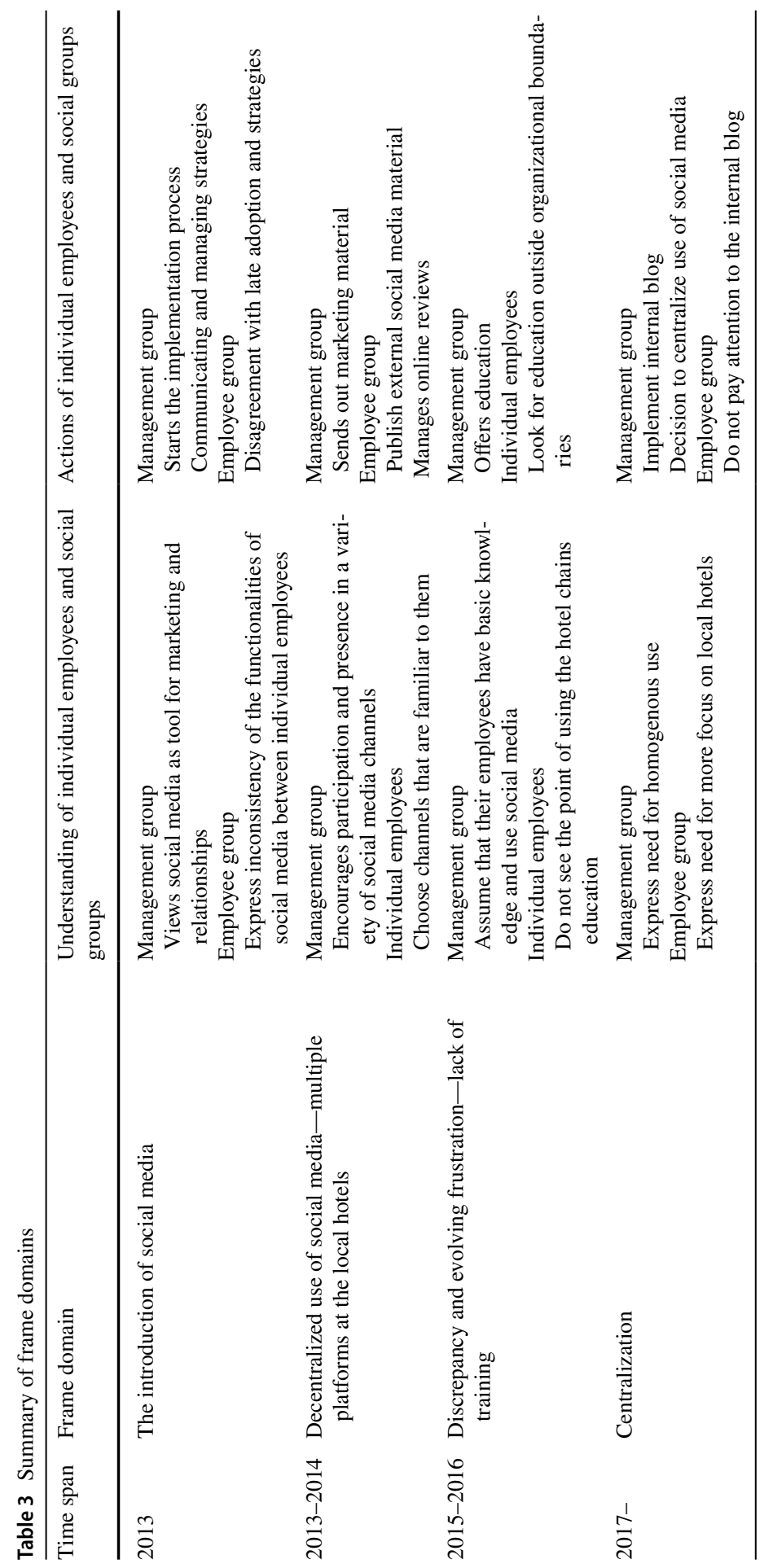




\section{Findings and analysis}

\subsection{The introduction of social media}

The studied hotel chain management decided to introduce social media in 2013. New positions were created to manage the change process: a social media manager was stationed at the hotel chain headquarters to develop guidelines for the entire chain and an e-commerce manager was hired to offer training in social media activities. The hotel chain's initial policy was that each individual hotel was in charge of its own social media usage and activities, i.e., they chose what social media platforms they wanted to be active in. Furthermore, the hotel chain management interpreted social media as easy to use and expressed assumptions that their employees had the knowledge and know-how, which refers to the nature-of-technology frame domain (cf. Orlikowski and Gash 1994). However, the hotel chain had policies, "does and don'ts," and sent out general information and marketing material about the chain that the hotels were expected to publish in social media platforms along with the material they produced themselves. The initial interviews showed an unclear strategy and vague policies. From the start in 2013, the management group consisted of a social media manager (Alan), and an e-commerce manager (Amanda), whose primary interpretation of social media in the hotel context was that it was a tool for engaging with customers online. Amanda, the e-commerce manager, presents her view in 2013 on the use of social media at the hotels (technology strategy):

It's about the online journey. It's about following the customer on his journey and proposing our hotel at the right moment.

The quote from Amanda illustrates the usefulness of social media from the hotel chain management perspective and reveals that this usefulness is closely related to creating relationships with customers online, which corresponds to earlier research (e.g. Kim et al. 2015a, b). The findings show that the employee group was positive towards (congruent with) the hotel chain's decision (technology implementation and technology strategy) to use social media but critical that the decision, according to individual opinions, took too long. Carl, one of the managers explains his standpoint:

As I understand it, they [hotel chain] were afraid that the brand would sprawl too much. And I think that because of that they were late, they had to create some kind of standard for how and where we should be seen. That's when they hired that guy who would be responsible [social media manager], then everything was controlled. Maybe too controlled. We went from nothing to having schedules for what we should post on Facebook and Twitter and stuff like that.

The follow-up-interview with Carl made 2 years later reveals an unchanged approach to the hotel chain's management of social media, which was also evident in the other interviews. He says:

Nothing has changed really, more than that there is more control and that the hotel chain wants us to measure everything. 


\subsection{Decentralized use of social media: multiple platforms at the local hotels}

The technology implementation and technology use (Orlikowski and Gash 1994) took place at each of the local hotels where the employees were in charge of using social media. The local hotels had the mandate to choose who would be in charge and this role often ended up with the sales manager or marketing manager. In practice this meant that they posted social media content and managed customer complaints, that is, the social media management included both external and internal social media use (Van Osch and Coursaris 2013). All of the employees had backgrounds in the hotel industry and a majority of them had worked their entire careers at hotels. The employees' group perception of social media use in the workplace context indicated that first of all they see that the usefulness of social media is highly connected to marketing and that they interpret the adoption of social media on a hotel chain level as a new way of marketing themselves. However, they also point out the need for answering customers' requests and online reviews in social media platforms and often put more effort into answering rather than being active and posting content themselves. Similar results have been found in earlier research (Kim et al. 2015a, b; Viglia et al. 2018). The employee group describes the guidelines (technology strategy) provided by the management group as focused on marketing strategies, sales, does and don'ts, and what type of tone and words should be used in social media platforms. Over the 4 years the employee group describes difficulties of knowing what to post but also what language to use. Since they are part of an international hotel chain they feel the need to use English to meet an international audience, but they also want to be attractive to their domestic audience. Emma, a sales manager at a local hotel, says in 2014:

We use three languages, English, German and Dutch. It's a bit problematic because every post get very long but we want to reach both our international customers and the ones nearby.

In 2017 Emma says:

We only use English now, because the hotel chain wanted us to. I personally don't think it is good because I want our followers in the city to be interested in what we have to say as well.

Overall, the employees' frames of technology in use did not change over time, but instead were strengthened during the 4 years of the study. This also relates to Young et al.'s (2016) technology implementation domain, that is, the hotel chain has not succeeded in communicating how they want the individuals to integrate social media as a part of their daily routines.

\subsection{Discrepancy and evolving frustration: lack of training}

Several of the employees do not approve of the social media guidelines while others think they are acceptable, which indicates a difference of frames concerning technology in use. Hence, the employees choose what social media platforms to 
use based on their own frames rather than the strategy used by the hotel chain. The employees describe that being responsible for social media presence and activities in their respective organization is laid "on top of everything else", and that they are not given more time to focus on social media activities. They also express that they do not prioritize social media activities since other work tasks are viewed as more important, which also makes their social media presence irregular with focus on solving "emergencies" like negative online reviews or customer complaints (cf. Anderson 2012). These statements also illustrate the usefulness of using the approach of studying organizational social media (Van Osch and Coursaris 2013) since it points to how individuals interpreted the usefulness and what social media platforms are more important than others. The employee group has different views on what kind of training and education the hotel chain offers. During the first interviews made in 2013-2014, in the very beginning of the introduction phase, the employee group revealed that some of them were aware of the offered education and others were not. This is while the hotel chain management stated that one of their most important tasks was to provide the local hotels with guidelines and education. Anna, a manager at one of the local hotels, says in 2015: "We do have some guidelines with pronunciation and words you can use, that's it." Other employees express that there are guidelines but that they do not approve of them. This is expressed by Carl, a managers at one of the local hotels, in 2014:

There is no proper training in how to use it [social media]. There are some guidelines and some “does and don'ts" like don't hurt the brand...that's it...

The employee group express that they have found their own ways of using social media instead of following the guidelines from management, which reflects the frame incongruence between the management group and the employees at the local hotels. Due to the fact that the different managers at the local hotels did not agree with or want to follow the strategy and guidelines provided by the hotel chain, the actual use (technology in use) was affected and a large discrepancy between the use of social media between the different local hotels could be observed. Robert, a manager at one of the local hotels, describes in 2014 that he did not care about the hotel chains guidelines by saying:

When I got the responsibility to work with social media, I went around to all our departments and asked for persons who were good at social media and then we sat down together and tried to figure out what we should do with social media. Everyone, people from the restaurant, from reception gave ideas about what we should do.

The statement above illustrates the employees' attitude towards social media that sustained during the 4 years. Statements from the employee group hence reveal that the employees both looked internally and at other organizations' or competitors'(external) social media content when looking for best practices and imitated them when they used social media at their hotels. This also illustrates how frames outside the organizational boundaries (cf. Davidson 2006) can have 
profound impacts on individual frames and the perceived usefulness. The hotel chain's strategy and guidelines did not manage to dominate or affect the frames held by the employee group. Instead, the employee group frames were affected by dominant frames outside of the organizations (cf. Davidson 2006) that had great implications for their use and understanding of social media. During the 4 years the frames of the employee group did not change considerably regarding the usefulness of social media and many of them had difficulties finding the usefulness of social media in relation to their work at the hotels and the value it could bring, which refers to different frames of contextual insights (cf. Young et al. 2016). As a result, the hotels' use of social media was inconsistent, irregular and extremely dependent on individual employees' interpretation of the usefulness of social media.

Furthermore, the inconsistency and incongruence were highly related to organizational learning, or non-learning. As argued above, organizations and their members need to both learn and unlearn, i.e., reframe, assumptions and knowledge related to the new IT in order to adapt to it (Bolman and Deal 1991; Argyris 1993). It is evident that neither the hotels nor the individual employees look at the old "problems" or routines from a new perspective, i.e., they do not act as if social media can be merged into existing organizational routines and processes (Feldman and Pentland 2003). The conflict and discrepancy between the management group and the employee group illustrates the process of negotiation that needs to occur in order for organizational learning to happen (Argyris 1993). This can also be interpreted as a poor strategy implementation on the part of hotel chain management. However, neither the management group nor the employee group "reframe" (Orlikowski and Gash 1994) or "unlearn" and as a result, organizational learning does not occur (Argyris 1993). The empirical data illustrates that the employee group does not "forget" (Bettis and Prahalad 1995) or make room for new logics and interpretations (Prahalad and Bettis 1986) of social media, which is necessary in order to make way for new cognitive logics. Instead, many of them hold on to frames and logics concerning social media created outside the organizational context, which prevents them from reframing and affects their use of organizational social media (Orlikowski and Gash 1994).

Another important aspect that affected the discrepancy in performance was the employee group's frames from private use of social media. Many of the employees expressed a limited usage of social media in their private life while others use social media heavily. The employees' frames of social media were highly related to the negative aspects of social media use, e.g., the lack of privacy which is described as the main reason for not using social media in their private lives. Interestingly, the employees also let frames created in their private lives concerning social media affect their assumptions about the usefulness of social media in the hotel context, hence they did not reframe their assumptions about social media in a workplace context. For example, they did not approve of publishing marketing material as social media content since they believed it was "annoying" and "destroyed" their social media platforms. This derives heavily from their experiences and expectations (frames) of social media in their private lives and what they appreciate about social media for leisure use, not as a professional IT in a workplace context. Nathan, a 
manager at a local hotel, explains why he does not use social media in his private life at the interview conducted in 2014 and in 2016:

I've never done it [used social media in private life], I've never really cared about it, in my world, it's been no, no! I never liked social media but I have been very good at it, for some strange reason, because I am interested in it, in behaviors and stuff.

The quote above illustrates that the sprawl and irregular use of social media is closely related to the employee's personal use of social media, the ones who use it in their private lives also use it regularly in their workplace (Treem et al. 2015). Interestingly, the employees that did not use social media in their private lives did not use the training offered by the hotel chain, hence we analyze their existing frames (Orlikowski and Gash 1994) as strong and that they had a strong resistance towards change. Interestingly, even though the employees had all worked in sales and marketing, they did not emphasize that social media should be used for this purpose, which indicated that they were strongly affected by private social media use and did not assume that social media makes sense as a marketing tool (Orlikowski and Gash 1994; Treem et al. 2015). These findings highlight the value of the longitudinal nature of the case study since they help explain what frames the employee group developed, or did not develop, concerning organizational social media.

\subsection{Centralization of social media use}

The unchanged frames of the employee group over time was revealed in a discrepancy of frames between the hotel management group and the employee group. This example of frame incongruence (Orlikowski and Gash 1994) escalated during the 4 years of the study and had major implications for the social media use over time. The hotel chain management group evidently did not succeed in providing dominant frames (Orlikowski and Gash 1994) concerning how to use social media and for what purpose. In 2013 and 2014, in the introduction phase, the employees expressed concerns that the chain sends them information and marketing material that they have to post in their social media. This caused a lot of frustration and even anger from the employee group who felt that they were being stampeded by the hotel chain, which illustrates the incongruence between management and employees (Orlikowski and Gash 1994). This also illustrates the high interpretative flexibility (Treem et al. 2015) the employees had on the usefulness of social media.

Carl one of the managers illustrates his frustration in 2014 by saying:

I feel that it is not relevant for us [the hotels] to post everything, I also think that the people who are responsible for these aspects [head office] have realized that there is no relevance in it and it is not relevant for us [hotels] to push for a weekend in Nice, and it is an important marketing channel, and I think we lose credibility in those channels and we lose followers, and then it quickly goes downhill... 
During a follow-up-interview in 2016, his frames concerning the technology strategy are practically the same and he still felt stampeded by the hotel chain. These sustained frames were observed in all of the follow-up interviews. The hotel employee's frames were under pressure to change during the 4 years of the study. One example of this is how the hotel chain in 2015 started an enterprise blog as a channel where all employees and managers, not just the ones in charge of social media, could post anything they wanted and other hotels within the chain could use the material or be inspired. The employees had different interpretations of this newly implemented intranet. Some of them were not aware that it existed while others were very positive, or in contrast, skeptical about it. Emma, one of the local managers, was unaware of the intranet until she visited the hotel chain headquarters in 2015: "We have an intranet where you can log in and follow actions and you can choose pictures to use. For us that was new, we didn't know it was there." Dan, a manager at one of the local hotels, describes in 2016 that he is very positive towards the blog, since he feels that it gives him an opportunity to practice and see how other employees use social media. He explains:

You can put up anything from posting any sales activity, or take a picture of it to post it, tell if you have taken a course... or you can take a picture of your CEO when he's visiting China.

The quotes above illustrate rather different interpretations of the usefulness (technology strategy and technology in use) of social media among the employee group and the management group. This is arguably a result of the fact that the employees did not follow the social media policies and did not want to post the content provided by the management group. Their frames concerning the technology strategy and technology-in-use were evidently strong and consistent during the four-year period the study was conducted. Hence, despite the effort of commencing dominant frames from the hotel management's side, the dominant frames of the employee group were not changed, which also illustrates how strong their frames concerning social media were during those 4 years. Furthermore, it also emphasizes that the frames of social media created outside organizational boundaries are very difficult to change.

The intent to create congruent frames (cf. Orlikowski and Gash 1994) by means of the enterprise blog evidently failed. Because of the failed negotiation of best practice, or the creation of congruent frames, the management decided to centralize social media use in late 2016. At the same time, the decision to close down all social media platforms except Facebook and Instagram was made. These platforms were connected to and had the names of the individual hotels but were managed centrally. The respondents explain that the decision to centralize social media use came from a large discrepancy between what the management wanted to do and what the employees actually did. Uma, a social media manager at the hotel chain level, explains in 2017 that the new way of using social media was challenging because they were more distant from the customers. She says: 
I have to pretend like I am present at the hotels and sometimes I ask the staff at the hotels to take a picture at the hotel and post it to me so that I can post it on Facebook and make it look like I'm actually at the hotel.

The process described above also illustrates how the incongruence of frames (Orlikowski and Gash 1994) between management and employees enhanced a need for the hotel chain to centralize social media in order to control and manage the social media outcome. Furthermore, it illustrates that the hotel chain management group had more flexible, changeable frames then the employee group, hence they changed their way of interpreting the usefulness of social media during the 4 years. One example of this is that even though in 2013 they argued that social media should be used by the hotels in order to be close to their customers, they drastically changed their point of view and centralized the social media use due to poor performance in social media by the local hotels. It can be argued that the consistent frames of social media that the employee group had created outside the organizational context (Orlikowski and Gash 1994; Treem et al. 2015) were strong and difficult to change, and therefore the employees were unable, or unwilling, to change their perspectives on the usefulness of social media. As a result, the hotels' use of social media was inconsistent, irregular and extremely dependent on individual employees' interpretation of the usefulness of social media.

\section{Conclusions}

The present study contributes to the literature on social media implementation and use in organizations, by identifying the technological frames (perceptions, assumptions and knowledge about IT) of organizational groups. The first research question was examined by identifying the technological frames of the two organizational groups, employee group and hotel management group, over a period of 4 years. These technological frames involved nature-of-technology, technology-in-use frame, technology-strategy frame, technology implementation and contextual insights (Orlikowski and Gash 1994; Young et al. 2016) and revealed unchanged frames by the individual employees and employee group and more flexible, changed frames by the hotel chain management. Furthermore, the study makes a theoretical contribution by investigating the organizational effects of these frames over a period of 4 years.

The study makes theoretical contributions by going one step further then the majority of earlier research when it comes to dominant frames held by individuals and organizational groups within organizations. The study shows that the dominant frames were created outside the organizational boundaries and mainly remained unchanged over time. This caused a discrepancy in use and reframing did not occur. The analysis revealed both frame incongruence between groups as well as inconsistencies within groups, resulting in frustration both from a management and employee point of view. The incongruence between groups revealed poor strategy implementation from the hotel chain management and a failure in understanding how to 
change dominant frames held by the employee group. Furthermore, the inconsistencies within the employee group were derived from different private frames of social media use that were highly influential in the professional use of social media.

The study also contributes to the literature on organizational social media use (cf. Van Osch and Coursaris 2013). The interpretative case study provides understandings of actions and cognitive processes related to organizational social media use. By focusing on a more general social media use, including social media use within the organizations such as the internal blog, as well as external use, e.g., social media used for marketing, the empirical data demonstrates the ongoing use and sense-making of social media. As the result shows, despite strategies and efforts to educate the employees in their use of social media, the strategies were not used and hence there was a major discrepancy in use. Furthermore, organizational learning did not occur, due to the lack of reframing within the employee group and hence the social media use was centralized by the hotel chain in order to create control over the content and eliminate discrepancies. The study also contributes to the hospitality research and service research by providing empirical knowledge on how organizational social media is used in hotel organizations over time. However, the empirical findings in this paper may be limited due to the case study of one hotel chain. The dynamics and employee turnover that characterize this industry furthermore limited the longitudinal study, hence it focuses on a rather small sample. Other hotel chains, organizations and industries might have different technological strategies and organizational cultures that affect the construction of employees' frames and we therefore encourage more research in this field.

From a practitioner's perspective, the findings call for more attention to how social media are implemented in organizations and how the strategies are communicated and used related to employees' sense-making processes. Furthermore, by examining the social media use over time the post-implementation phase is emphasized, which offers valuable insight into how to manage these sense-making processes over time and the implications they might have. Therefore, the result of our study can be helpful for practitioners when introducing and using social media in an organizational context over time.

Open Access This article is distributed under the terms of the Creative Commons Attribution 4.0 International License (http://creativecommons.org/licenses/by/4.0/), which permits unrestricted use, distribution, and reproduction in any medium, provided you give appropriate credit to the original author(s) and the source, provide a link to the Creative Commons license, and indicate if changes were made.

\section{Appendix 1: List of respondents}

\begin{tabular}{llll}
\hline $\begin{array}{l}\text { Respondents "Int. hotel } \\
\text { chain" }\end{array}$ & Position & Age & $\begin{array}{l}\text { Number of } \\
\text { interviews }\end{array}$ \\
\hline Alan & Social media manager & 50 & 2 \\
Amanda & E-commerce manager & 35 & 1 \\
Anna & Sales manager & 34 & 2 \\
\hline
\end{tabular}




\begin{tabular}{llll}
\hline $\begin{array}{l}\text { Respondents "Int. hotel } \\
\text { chain" }\end{array}$ & Position & Age & $\begin{array}{l}\text { Number of } \\
\text { interviews }\end{array}$ \\
\hline Billy & Customer relationship manager & 38 & 2 \\
Carl & Sales manager & 25 & 2 \\
Dan & Sales and marketing manager & 50 & 2 \\
Emma & Marketing manager & 35 & 2 \\
Fiona & Sales manager & 33 & 2 \\
Greta & Marketing manager & 40 & 2 \\
Hanna & Sales manager & 35 & 2 \\
Ivar & Marketing manager & 35 & 1 \\
Jessica & Sales manager & 40 & 1 \\
Karen & Hotel manager & 50 & 1 \\
Louise & Marketing manager & 40 & 1 \\
Maria & Sales coordinator & 25 & 1 \\
Martin & Marketing manager & 35 & 1 \\
Nathan & Sales manager & 30 & 1 \\
Olga & Marketing manager & 40 & 1 \\
Oscar & Sales coordinator & 25 & 1 \\
Penny & Sales manager & 45 & 1 \\
Patricia & Marketing manager & 45 & 1 \\
Robert & Sales manager & 45 & 1 \\
Sally & Marketing manager & 45 & 1 \\
Samuel & Hotel manager & 50 & 1 \\
Trey & E-Commerce manager & 45 & 1 \\
Uma & Social media manager & 35 & 1 \\
Vera & Social media manager & 30 & 1 \\
Wilma & Social media content manager & 30 & 1 \\
\hline & & & 1 \\
& & & 1 \\
\hline & & & 1 \\
\hline
\end{tabular}

\section{Appendix 2: Interview guide 1}

Questions asked at first round of interviews.

1. How old are you?

2. How long have you worked here?

3. What education do you have?

4. How long have you worked in the hotel industry?

5. Tell me about your function in the organization? What are your main responsibilities?

6. When did you start to use social media in your hotel activities?

7. Can you tell me about how you got started?

8. Can you describe how your hotel use social media?

9. Have you gotten any instructions from the hotel chain? 
10. What channels do you use? Why did you choose them?

11. What goals would you say that you have with social media marketing?

12. In what ways other than marketing do you use social media?

13. Can you describe your social media activities during an ordinary week?

14. What do you experience as the biggest challenges working with social media?

15. Do you measure your activities or ROI in social media marketing?

16. Did you have any education in social media?

17. How do you handle comments and questions that are asked by customers in social media?

18. Do you use social media in your private life?

19. Is there anything else concerning social media you would like to add?

\section{Appendix 3: Interview guide 2}

Questions asked at follow-up-interviews.

1. Can you describe what has happened with your social media use since we met last time?

2. Do you use the same social media channels?

3. Have there been any changes in you use of social media compared to last year?

4. Have you gotten any new directives from the hotel chain?

5. What have been the greatest challenges of using social media?

6. What have been the greatest advantages of using social media?

7. Have you got any education or training since the last time we met?

8. Are you planning any changes in your social media activities?

Can you describe what you experience that you have learned?

\section{References}

Anderson CK (2012) The impact of social media on lodging performance. Cornell Hosp Rep 12(15):4-12

Aral S, Dellarocas C, Godes D (2013) Introduction to the special issue-social media and business transformation: a framework for research. Inf Syst Res 24(1):3-13

Argyris C (1993) Knowledge for action: a guide to overcoming barriers to organizational change. JosseyBass, San Francisco

Ayeh JK, Au N, Law R (2013) "Do we believe in TripAdvisor?" Examining credibility perceptions and online travelers' attitude toward using user-generated content. J Travel Res 52(4):437-452

Barr H (1998) Competent to collaborate: Towards a competency-based model for interprofessional education. J Interprofessional Care 12(2):181-18

Bazeley PJK (2013) Qualitative data analysis with NVivo. SAGE, London

Berezina K, Bilgihan A, Cobanoglu C, Okumus F (2016) Understanding satisfied and dissatisfied hotel customers: text mining of online hotel reviews. J Hosp Mark Manag 25(1):1-24

Bettis RA, Prahalad CK (1995) The dominant logic: retrospective and extension. Strateg Manag J 16(1):5-14

Blegind Jensen T, Aanestad M (2007) Hospitality and hostility in hospitals: a case study of an EPR adoption among surgeons. Eur J Inf Syst 16:672-680 
Bolman LG, Deal TE (1991) Leadership and management effectiveness: a multiframe, multisector analysis. Hum Resour Manag 30(4):509-534

Bryman A, Bell E (2015) Business research methods. Oxford University Press, Oxford

Buhalis D, Neuhofer B (2017) Service-dominant logic in the social media landscape: new perspectives on experience and value co-creation. In: Advances in social media for travel, tourism and hospitality. Routledge, London, pp 13-25

Chan NL, Guillet BD (2011) Investigation of social media marketing: how does the hotel industry in Hong Kong perform in marketing on social media websites? J Travel Tour Mark 28(4):345-368

Cole M, Avison D (2007) The potential of hermeneutics in information systems research. Eur J Inf Syst 16(6):820-833

Crotts JC, Mason PR, Davis B (2009) Measuring guest satisfaction and competitive position in the hospitality and tourism industry: an application of stance-shift analysis to travel blog narratives. J Travel Res 48(2):139-151

Davis FD (1989) Perceived usefulness, perceived ease of use, and user acceptance of information technology. MIS Q 13(3):319-340

Davidson E (2002) Technology frames and framing: a socio-cognitive investigation of requirements determination. MIS Q 26:329-358

Davidson E (2006) A technological frames perspective on information technology and organizational change. J Appl Behav Sci 42(1):23-39

Davidson E, Pai D (2004) Making sense of technological frames: promise, progress, and potential. Information systems research. Springer, New York, pp 473-491

de Rosario AH, Rodríguez MDMG, Pérez MDCC (2013) Development of social media and web 2.0 in the top hotel chains. Tour Manag Stud 9(1):13-19

Di Pietro L, Pantano E (2012) An empirical investigation of social network influence on consumer purchasing decision: The case of Facebook. J Direct Data Digital Mark Pract 14(1):18-29

Ellison NB, Gibbs J, Weber MS (2015) The use of enterpris social network sites for knowledge sharing in distributed organizations: the role of organizational affordances. Am Behav Sci 59(1):103-123

Feldman M, Pentland B (2003) Re-theorizing organizational routines as a source of flexibility and change. Adm Sci Q 48:94-118

Fulk J (1993) Social construction of communication technology. Academy Manag J 931-950

Fulk J, Gould JJ (2009) Features and contexts in technology research: a modest proposal for research and reporting. J Comput Mediat Commun 14:764-770

Garrido-Moreno A, Lockett N (2016) Social media use in European hotels: benefits and main challenges. Tour Manag Stud 12(1):172-179

Garrido-Moreno A, García-Morales VJ, Lockett N, King S (2018) The missing link: creating value with social media use in hotels. Int J Hosp Manag 75:94-104

Hennig-Thurau T, Hofacker CF, Bloching B (2013) Marketing the Pinball Way: understanding how social media change the generation of value for consumers and companies. J Interact Mark 27(4):237-241

Högberg K (2017) Challenges of social media marketing - an explorative international study of hotels. Int J Technol Mark 12(2):127-141

Högberg K (2018) Organizational social media: a literature review and research Agenda. In: 2018 51th Hawaii international conference on system sciences (HICSS) proceedings, pp 1864-1873

Huang L, Yung CY, Yang E (2011) How do travel agencies obtain a competitive advantage?: Through a travel blog marketing channel. J Vacat Mark 17(2):139-149

Huang JJS, Yang SJH, Huang YM, Hsiao IYT (2010) Social learning networks: Build mobile learning networks based on collaborative services. Educ Technol Soc 13(3):78-92

Hsu CW (2009) Frame misalignment: interpreting the implementation of information systems security certification in an organization. Eur J Inf Syst 18(2):140-150

Järvinen P (2004) On research methods. Opinpajan Kirja, Tampere

Jian G (2007) Omega is a four-letter word: toward a tension-centered model of resistance to information and communication technologies. Commun Monogr 74:517-540

Kaplan AM, Haenlein M (2010) Users of the world, unite! The challenges and opportunities of social media. Bus Horiz 53(1):59-68

Kasavana ML, Nusair K, Teodosic K (2010) Online social networking: redefining the human web. J Hosp Tour Technol 1(1):68-82 
Kim SS, Im J, Hwang J (2015a) The effects of mentoring on role stress, job attitude and turnover intention in the hotel industry. Int J Hosp Manag 48:68-82

Kim WG, Lim H, Brymer RA (2015b) The effectiveness of managing social media on hotel performance. Int J Hosp Manag 44:165-171

Klein JI (1989) Parenthetic learning in organizations: toward the unearning of the unlearning model. J Manag Stud 26(3):291-308

Klein HK, Myers MD (1999) A set of principles for conducting and evaluating interpretive field studies in information systems. MIS Q 23(1):67-94

Kozinets RV (2010) Netnography. Doing ethnographic research online. Sage Publications, Thousand Oaks

Kvale S (1996) Interviews: an introduction to qualitative research interviewing. SAGE, Thousand Oaks

Kwon TH, Zmud RW (1987) Unifying the fragmented models of information systems implementation. In: Boland RJ, Hirschheim RA (eds) Critical issues in information systems research. John Wiley, New York, NY, pp 227-251

Larson K, Watson R (2011) The value of social media: toward measuring social media strategies. In: Thirty Second International Conference on Information Systems Shanghai. vol 2011, pp 1-18

Leonardi PM (2011) When flexible routines meet flexible technologies: affordance, constraint, and the imbrication of human and material agencies. MIS Q 35(1):147-167

Leonardi PM, Huysman M, Steinfield CW (2013) Enterprise social media: definition, history, and prospects for the study of social technologies in organizations. J Comput Mediat Commun 19:1-19

Lin A, Silva S (2005) The social and political construction of technological frames. Eur J Inf Syst 14(1):49-59

Lofland J, Lofland LH (2006) Analyzing Social Settings. Wadsworth Publishing Company, Belmont

Lu Y, Chen Z, Law R (2018) Mapping the progress of social media research in hospitality and tourism management from 2004 to 2014. J Travel Tour Mark 35(2):102-118

Majchrzak A, Faraj S, Kane GC, Azad B (2013) The contradictory influence of social media affordances on online communal knowledge sharing. J Comput Mediat Commun 19(1):38-55

Mansour O (2013) The bureaucracy of social media: an empirical account in organizations. Doctoral dissertation, Linnaeus University Press

Michaelidou N, Siamagka NT, Christodoulides G (2011) Usage, barriers and measurement of social media marketing: an exploratory investigation of small and medium B2B brands. Ind Mark Manag 40(7):1153-1159

Miles MB, Huberman AM (1994) Qualitative data analysis: an expanded sourcebook. SAGE, Thousand Oaks

Minazzi R (2015) Social media marketing in tourism and hospitality. Springer International Publishing, New York

Mishra AN, Agarwal R (2010) Technological frames, organizational capabilities, and it use: an empirical investigation of electronic procurement. Inf Syst Res 4:249-270

Mkono M, Tribe J (2017) Beyond reviewing: uncovering the multiple roles of tourism social media users. J Travel Res 56(3):287-298

Moro S, Rita P (2018) Brand strategies in social media in hospitality and tourism. Int J Contemp Hosp Manag 30(1):343-364

Munar AM (2012) Social media strategies and destination management. Scand J Hosp Tour 12(2):101-120

Nyangwe S, Buhalis D (2018) Branding transformation through social media and co-creation: lessons from marriott international. In: Information and communication technologies in tourism 2018. Springer, Cham, pp 257-269

Price J, Starkov M (2006) Building a blog strategy in hospitality: grow customer relationships and direct online revenue. http://www.hospitalitynet.org/news/4026867.html (consulted August 2007)

Olesen K (2014) Implications of dominant technological frames over a longitudinal period. Inf Syst J 24(3):207-228

Olesen K, Narayan AK, Ramachandra S (2013) Technological frames: influence of group frames (ingluence). Probl Perspect Manag 11(1):81-93

Orlikowski WJ (1992) Learning from notes: organizational issues in groupware implementation. In: Proceedings of the 1992 conference on computer supported cooperative work, Toronto, Canada, pp 362-369

Orlikowski WJ, Gash DC (1994) Technological frames: making sense of information technology in organizations. ACM Trans Inf Syst 12(2):174-207 
Pinch TJ, Bijker WE (1984) The social construction of facts and artifacts-or how the sociology of science and the sociology of technology might benefit each other. Soc Stud Sci 14:399-441

Podnar K, Javernik P (2012) The effect of word of mouth on consumers' attitudes toward products and their purchase probability. J Promot Manag 18:145-168

Prahalad CK, Bettis RA (1986) The dominant logic: a new linkage between diversity and performance. Strateg Manag J 7(6):485-501

Razmerita L, Kirchner K, Nabeth T (2014) Social media in organizations: leveraging personal and collective knowledge processes. J Organ Comput Electron Commer 24(1):74-93

Rogers EM (1995) Diffusion of innovations, 4th edn. The Free Press, New York

Schlagwein D, Hu M (2017) How and why organisations use social media: five use types and their relation to absorptive capacity. J Inf Technol 32(2):194-209

Sigala M, Gretzel U (eds) (2012) Social media in travel, tourism and hospitality: theory, practice and cases. Ashgate, Farnham

Sigala M, Gretzel U (eds) (2017) Advances in social media for travel, tourism and hospitality: new perspectives, practice and cases. Routledge, London

Silveira-Chaves M, Gomes R, Pedron C (2012) Analysing reviews in the Web 2.0: small and medium hotels in Portugal. Tour Manag 33(5):1286-1287

Sparks BA, Browning V (2011) The impact of online reviews on hotel booking intentions and perception of trust. Tour Manag 32(6):1310-1323

Treem JW, Leonardi PM (2012) Social media use in organizations: exploring the affordances of visibility, editability, persistence, and association. Commun Yearb 36:143-189

Treem JW, Dailey SL, Pierce CS, Leonardi PM (2015) Bringing technological frames to work: how previous experience with social media shapes the technology's meaning in an organization. J Commun 65:396-422

Van Osch W, Coursaris CK (2013) Organizational social media: a comprehensive framework and research agenda. In: System sciences (HICSS), 2013 46th Hawaii international conference on IEEE. January, pp 700-707

Van Osch W, Coursaris CK (2017) A strategic social action framework: theorizing and analyzing the alignment of social media affordances and organizational social action. J Organ Comput Electron Commer 27(2):99-117

Veal AJ (2011) Research methods for leisure and tourism: a practical guide, 4th edn. Prentice Hall, Harlow

Viglia G, Pera R, Bigné E (2018) The determinants of stakeholder engagement in digital platforms. J Bus Res 89:404-410

Weick KE (1990) Technology as equivoque: sensemaking in new technologies. In: Goodman PS, Sproull LS (eds) The Jossey-Bass management series. technology and organizations. Jossey-Bass, San Francisco, pp 1-44

Weick A (1994) Reconstructing social work education. J Teach Soc Work 8(1-2):11-30

Weick KE, Sutcliffe KM, Obstfeld D (2005) Organizing and the process of sensemaking. Organiz SCi 16(4):409-421

Wilson M, Howcroft D (2005) Power, politics and persuasion in IS evaluation: a focus on 'relevant social groups'. J Strateg Inf Syst 14:17-43

Xiang Z, Du Q, Ma Y, Fan W (2017) A comparative analysis of major online review platforms: implications for social media analytics in hospitality and tourism. Tour Manag 58:51-65

Yin RK (2003) Case study research: design and methods, 3rd edn. Sage, Thousand Oaks

Yoo Y (2010) Computing in everyday life: a call for research on experiential computing. MIS Q 213-231

Young BW, Mathiassen L, Davidson E (2016) Inconsistent and incongruent frames during it-enabled change: an action research study into sales process innovation. J Assoc Inf Syst 17(7):495

Zammuto RF, Griffith TL, Majchrzak A, Dougherty DJ, Faraj S (2007) Information technology and the changing fabric of organization. Organ Sci 18(5):749-762

Zhang Z, Liang S, Li H, Zhang Z (2019) Booking now or later: do online peer reviews matter? Int J Hosp Manag 77:147-158

Zhu F, Zhang X (2010) Impact of online consumer reviews on sales: the moderating role of product and consumer characteristics. J Mark 74:133-148

Publisher's Note Springer Nature remains neutral with regard to jurisdictional claims in published maps and institutional affiliations. 